\title{
The continuum of ovarian response leading to BIRTH, a real world study of ART in Spain
}

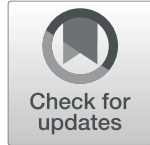

Marcos Ferrando ${ }^{1}$, Buenaventura Coroleu², Luis Rodríguez-Tabernero ${ }^{3}$, Gorka Barrenetxea ${ }^{4}$, Cristina Guix ${ }^{5}$ Fernando Sánchez ${ }^{6}$, Julian Jenkins ${ }^{7^{*}}$ (D) and on behalf of the BIRTH study group

\begin{abstract}
Background: The first biosimilar of recombinant follicle stimulating hormone (rFSH) launched in Europe was Bemfola ${ }^{\circledast}$ in 2014 following a clinical development programme demonstrating efficacy and safety to the satisfaction of the European Medicines Agency. Since then the increasing use of biosimilar rFSH has provided the opportunity to study both effectiveness across the whole population and the variation of $\mathrm{FFSH}$ use during routine clinical care in a real-world setting in Spain.

Methods: This is a real-world study of 1222 women treated in 26 assisted reproduction treatment centres throughout Spain providing experience of the use of a biosimilar recombinant follicle stimulating hormone in four distinct populations. The four populations studied were poor responders, suboptimal responders, normal responders and oocyte donors. The primary endpoint was the total number of oocytes retrieved. Secondary endpoints included number of days of rFSH stimulation, total dose of rFSH administered, number of MIl oocytes, number of fertilized oocytes, quality of embryos, number of embryos transferred, implantation rates, clinical pregnancy rates following embryo transfer, number of multiple pregnancies and number of serious adverse reactions, including moderate-to-severe OHSS.
\end{abstract}

Results: Differences were seen across the populations both in the characteristics of the women and ART outcomes suggestive of a continuum of fertility prognosis. In the poor responders, suboptimal responders, normal responders and oocyte donor populations the mean age in years was $39.9( \pm$ SD 3.4), $38.4( \pm S D 2.9), 34.4( \pm S D 3.3)$ and $26( \pm S D$ 4.6) respectively and number of oocytes retrieved was 4.1 ( \pm SD 2.7), 8.6 ( \pm SD 6.0), $12.2( \pm$ SD 7.2) and 19.5 ( \pm SD 9.5) respectively. The proportion of embryos graded as best quality was $18.5 \%, 33.0 \%$ and $43.8 \%$, and graded as worst quality was $20.4 \%, 5.8 \%$ and $5.8 \%$ for poor responders, suboptimal responders and normal responders respectively. In a similar pattern, for poor responders, suboptimal responders and normal responders the implantation rates were $16.0 \%,(8 / 50), 22.4 \%$ (49/219), 30.6\% (97/317) respectively and clinical pregnancy rates were $23.2 \%(10 / 43), 30.4 \%$ (59/194) and $37.0 \%$ (114/308) respectively. Adverse events were reported in only 7 of 1222 women (0.6\%).

Conclusions: Overall the results were consistent with the national ART results reported for Spain, hence this study provides reassurance of the clinical effectiveness of a biosimilar rFSH used in a real world setting.

Trial registration: ClinicalTrials.gov identifier - NCT02941341.

Keywords: IVF, Biosimilar, FSH, Real world study, Combination protocols, Follitropin CRS, Bemfola

\footnotetext{
* Correspondence: julian.jenkins@preglem.com

${ }^{7}$ Gedeon Richter/Preglem S.A., Gedeon Richter/ Preglem SA, Route de

Frontenex 41A, 1207 Geneva, Switzerland

Full list of author information is available at the end of the article
}

(c) The Author(s). 2020 Open Access This article is licensed under a Creative Commons Attribution 4.0 International License, which permits use, sharing, adaptation, distribution and reproduction in any medium or format, as long as you give appropriate credit to the original author(s) and the source, provide a link to the Creative Commons licence, and indicate if changes were made. The images or other third party material in this article are included in the article's Creative Commons licence, unless indicated otherwise in a credit line to the material. If material is not included in the article's Creative Commons licence and your intended use is not permitted by statutory regulation or exceeds the permitted use, you will need to obtain permission directly from the copyright holder. To view a copy of this licence, visit http://creativecommons.org/licenses/by/4.0/ The Creative Commons Public Domain Dedication waiver (http://creativecommons.org/publicdomain/zero/1.0/) applies to the data made available in this article, unless otherwise stated in a credit line to the data. 


\section{Background}

The European IVF-monitoring Consortium (EIM) for the European Society of Human Reproduction and Embryology (ESHRE) estimated that in 2014 one in every 50 children born in Europe were the result of Assisted Reproductive Technology (ART) treatments [1]. Furthermore, in 2014 Spain reported to the EIM a total of 109,275 ART treatments, which was higher than any other European county [1]. Gonadotrophin treatment contributes a significant proportion of the cost of ART, thus the introduction of biosimilars of recombinant follicle stimulating hormone $(\mathrm{rFSH})$ alpha may alleviate the costs of ART improving affordability [2]. The first $\mathrm{rFSH}$ biosimilar launched in Europe was Bemfola $^{\circ}$ in 2014 [3], which has proven popular in Spain [4]. A second rFSH biosimilar, Ovaleap", was approved in Europe in 2013 and launched in 2016 [3].

The basis of the demonstration of equivalence between a biosimilar and the reference product primarily relies on exhaustive, highly sensitive physicochemical and biological activity comparability assessments later supported by clinical studies leading to a total development time of typically 6 to 12 years [3]. For biosimilar $\mathrm{rFSH}$ development the European Medicines Agency (EMA) recommends the "number of oocytes retrieved" as the primary endpoint to demonstrate comparability of clinical efficacy against the reference product, as pregnancy rates are influenced by multiple factors unrelated to ovarian stimulation [5]. The Bemfola $^{\circ}$ manufacturing conditions, characterization and impurity profile, specifications and stability were all in full compliance with EMA standards [3]. Although biological medicines, both originators and biosimilars, will have inherent variability due to their biological source leading to batch to batch variability, the EMA did not consider there were any differences between Bemfola $^{\bullet}$ and Gonal- $\mathrm{f}^{\ominus}$ that would have a significant impact on the product's safety and efficacy [3]. A pharmacokinetic study of 23 healthy female volunteers revealed no appreciable differences in key pharmacokinetic parameters between Bemfola $^{\circ}$ and Gonal- $f^{\bullet}[6]$. The pivotal, randomized, multinational, phase 3 European approval study for Bemfola ${ }^{\circ}$ versus Gonal- $\mathrm{f}^{\ominus}$ was on a population of 372 women aged 20 38 years undergoing upto two IVF/ICSI cycles with typical exclusion criteria including prior excessive or inadequate ovarian response [7]. This study demonstrated equivalence of the two products in the number of retrieved oocytes against a pre-determined clinical equivalence margin of \pm 2.9 oocytes; Bemfola ${ }^{\circ}$ yielded $10.8 \pm 5.11$ oocytes versus Gonal- $\mathrm{f}^{\circ} 10.6 \pm 6.06$ oocytes, mean difference: $0.27,95 \%$ confidence interval: -1.34 , 1.32. Also a similar clinical pregnancy rate per embryo transfer was observed in first and second cycles
(Bemfola : 40.2 and $38.5 \%$ vs Gonal-f $f^{\circ}$ : 48.2 and $27.8 \%$, respectively). No difference was seen in severe ovarian hyperstimulation syndrome rates between treatment groups (Bemfola: 0.8\%; Gonal-f: $0.8 \%$ ) nor overall safety profiles with no evidence of immunogenicity in either group.

Beyond the demonstration of efficacy in carefully controlled phase 3 clinical trials on selected populations, the value of assessing the effectiveness of new treatments across the whole population undergoing routine clinical care in a real-world setting is becoming increasingly recognised [8]. The EU Medicines Agencies Network Strategy to 2020 drew attention to the value of real-world studies to assess effectiveness of new drugs in a real world setting and even in sub populations [9]. The BIRTH study was a post approval, noninterventional study on the use of Bemfola ${ }^{\circ}$, assessing the effectiveness of Bemfola in 4 different populations undergoing ART in Spain. Furthermore, the BIRTH study provides a snap shot of ART practice in Spain revealing important differences in the populations undergoing ART.

\section{Methods \\ Study design}

The BIRTH study was a post EMA approval, noninterventional study of women who had undergone oocyte retrieval after ovarian stimulation with Bemfola ${ }^{\circ}$ with $\mathrm{GnRH}$ antagonist pituitary-suppression, either as part of an autologous in vitro fertilisation (IVF) / intracytoplasmic sperm injection (ICSI) treatment cycle or for oocyte donation. Other than the latter requirements treatment was according to the centres' standard of care. In $28 \%$ of autologous embryo transfers all embryos had been cryopreserved and embryo transfer delayed. The study was carried out in 26 Spanish Assisted Reproduction centres, both public and private, belonging to 10 regions throughout Spain.

The study was designed by the sponsor (Finox Biotech Iberia, S.L., which in June 2016 was acquired by Gedeon Richter Ibérica S.A) supported by a group of Spanish ART experts. The study was approved by the Ethics Committee of Clinical Research of Euskadi (CEIC-E). Enrolment was conducted from September 2016 until April 2018 with the data collected and analysed by Dynamic, Azcona, 3,128,028 Madrid, Spain. All authors were involved in the preparation of the paper and validate the accuracy of the data.

\section{Study population}

Women aged $\geq 18$ years at recruitment, either patients undergoing an IVF/ICSI procedure or egg donors who completed a controlled ovarian stimulation receiving at least 5 doses of Bemfola ${ }^{\circ}$ were included in the study. 
Pituitary suppression was achieved by administering $\mathrm{GnRH}$ antagonists. All participating women signed an Informed Consent Form, prior to any data collection. Women reporting hypersensitivity to follitropin alfa or to any of the excipients of Bemfola ${ }^{\circ}$ were excluded. The presence of a pituitary or hypothalamic tumour was also an exclusion criteria.

Patients were divided into four populations (poor responders, suboptimal responders, normal responders and oocyte donors) defined as follows. Poor responders were defined according to the Bologna definition of having at least two of the following criteria: advanced reproductive age ( $\geq 40$ years) or any other risk for poor ovarian response; previous poor ovarian response $(\leq 3$ oocytes with a conventional protocol of stimulation, and abnormal ovarian reserve results - antral follicle count $<5$ to 7 follicles, anti-mullerian hormone $(\mathrm{AMH})<0.5-1.1 \mathrm{ng} / \mathrm{ml}$ [10]. Suboptimal responders were defined according to two subsets; firstly, women aged < 38 years with either a previous poor ovarian response ( $\leq 3$ oocytes) with a conventional protocol or abnormal ovarian reserve tests (AFC $<5$ follicles, $\mathrm{AMH}<0,5 \mathrm{ng} / \mathrm{ml})$. The second subset of patients defined as suboptimal responders were those women aged $>37$ years without any of the features described above, but according to routine clinical practice were stimulated with > 225 IU of FSH in combination with $\mathrm{LH}$ activity from human menopausal gonadotropin (HMG) or recombinant luteinising hormone $(\mathrm{rLH})$. Normal responders were defined as women aged $<38$ years with no risk factors of poor ovarian reserve $(\mathrm{AMH}<1.5 \mathrm{ng} /$ $\mathrm{ml}$, endometriosis grade I-II, previous poor ovarian response) and women with high ovarian reserve, including women with polycystic ovary syndrome.

\section{Measurements}

The primary endpoint was the total number of oocytes retrieved. Secondary endpoints included number of days of $\mathrm{rFSH}$ stimulation, total dose of $\mathrm{rFSH}$ administered, number of MII oocytes, number of fertilized oocytes, quality of embryos, number of embryos transferred, implantation rates, clinical pregnancy rates following embryo transfer and number of multiple pregnancies. To support routine post marketing pharmacovigilance monitoring moderate-severe ovarian hyperstimulation syndrome (OHSS) and serious adverse reactions were recorded.

\section{Statistical analysis}

Since the purpose of this study was purely descriptive, no formal sample size calculations based on comparative hypothesis testing were conducted but rather the sample size was based on ensuring a suitable size to describe the effectiveness of Bemfola ${ }^{\circ}$ in routine use. As this was a real world study doctors were free to treat patients as they felt appropriate and there was no randomisation nor stratification into study groups. It would thus be anticipated that there would be considerable heterogeneity within groups, which may be subject to a number of biases. Accordingly, the data is only provided descriptively using appropriate methodology to avoid misleading the reader with any attempt at comparative analyses, which would be inherently flawed.

\section{Results}

A total of 1222 women were available for data analysis divided into four populations: poor responders $(n=96)$, suboptimal responders $(n=301)$, normal responders $(n=386)$ and oocyte donors $(n=439)$. Data were not collected from the oocyte recipient treatment cycles and patient flow for each population throughout treatment is summarised in Table 1, which also provides details of the completeness of the data.

As expected, there were differences in demographic profile among the assessed populations of women (Table 2). Despite higher total amount of gonadotrophin stimulation in the poor responder and suboptimal responders, these populations produced both fewer total number of oocytes and fewer metaphase two oocytes compared to the normal responders and oocyte donors (Table 3). Despite differences in the number of fertilised oocytes between the populations the eventual number of embryos transferred did not differ greatly between them (Table 4). However, the proportion of embryos graded according to the criteria of the Asociación para el Estudio de la Biología de la Reproducción (ASEBIR) $[11,12]$ as best quality was $18.5 \%, 33.0 \%$ and $43.8 \%$ and worst quality was $20.4 \%, 5.8 \%$ and $5.8 \%$ for poor responders, suboptimal responders and normal responders respectively (Fig. 1). Further, the normal responder population had both a better implantation rate and more pregnancies compared to the poor responder and suboptimal responder populations (Table 5).

The data was further analysed with respect to the use of $\mathrm{rFSH}$ alone in monotherapy protocols or with a product having LH activity in combination protocols (Tables 6, 7 and 8). Across the full study population, combination protocols were used in $28.7 \%$ of women less than 35 years and $59.6 \%$ of women 35 years of age or older. Within each of the populations, combination protocols were used in $54.5 \%$ of poor responders, $67.5 \%$ of suboptimal responders, $38.1 \%$ of normal responders and $25.9 \%$ of oocyte donors. Within each population the number of retrieved oocytes, implantation rates and clinical pregnancy rates 
Table 1 Patient Flow and completeness of data recording

\begin{tabular}{|c|c|c|c|c|c|}
\hline Populations & Total & $\begin{array}{l}\text { Poor } \\
\text { Responders }\end{array}$ & Suboptimal Responders & $\begin{array}{l}\text { Normal } \\
\text { Responders }\end{array}$ & $\begin{array}{l}\text { Oocyte } \\
\text { Donors }\end{array}$ \\
\hline All evaluable patients ( $n$ ) & 1222 & 96 & 301 & 386 & 439 \\
\hline Cycles proceeding to oocyte retrieval (n) & 1169 & 88 & 274 & 378 & 429 \\
\hline Number of cycles where oocyte number recorded (n) & 1169 & 88 & 274 & 378 & 429 \\
\hline Cycles with Oocytes fertilized (n) & 642 & 58 & 240 & 344 & NA \\
\hline Cycles with Embryos Transferred (n) & 546 & 43 & 194 & 309 & NA \\
\hline $\begin{array}{l}\text { Number of cycles where number of embryos transferred } \\
\text { recorded }(n)\end{array}$ & 362 & 33 & 135 & 194 & NA \\
\hline $\begin{array}{l}\text { Number of embryo transfer cycles where outcome of cycle } \\
\text { known (n) }\end{array}$ & 533 & 41 & 191 & 301 & NA \\
\hline Cycles resulting in clinical Pregnancy (n) & 183 & 10 & $59^{a}$ & 114 & NA \\
\hline $\begin{array}{l}\text { Number of cycles where number of gestation sacs } \\
\text { recorded (n) }\end{array}$ & 182 & 10 & 59 & 113 & NA \\
\hline
\end{tabular}

${ }^{\mathrm{a}}$ In addition, there was one ectopic pregnancy

$N A=$ not appropriate

tended to be lower with combination protocols than monotherapy protocols (Tables 7 and 8).

\section{Pharmacovigilance data}

There were only 7 out of the 1222 women (0.6\%), in whom adverse events were reported. Ovarian hyperstimulation syndrome (OHSS) of at least moderate severity occurred in 1 case in the suboptimal responder population and in 4 cases of the normal responder population, of which 1 case was reported as severe OHSS. In addition, two serious adverse events were reported. One patient (out of 386), in the normal responder population, reported severe pain after egg retrieval. One oocyte donor (out of 439 women) reported a Bell's palsy, which was considered unrelated to medication. All adverse events reported during the study were collated with adverse events reported directly to the Gedeon Richter pharmacovigilance department and the consolidated pharmacovigilance data is presented in this manuscript.

\section{Discussion}

By studying four populations of women (poor responders, suboptimal responders, normal responders and oocyte donors) the BIRTH study shows a clear and related continuum of ovarian response and fertility among women. The majority of patients were not classified consistently across all centres with a clear sole cause of infertility illustrating the complexity of understanding the cause of infertility and agreeing to a common

Table 2 Demographic and baseline details of all patients

\begin{tabular}{|c|c|c|c|c|c|}
\hline & $\begin{array}{l}\text { All women } \\
(n=1222)\end{array}$ & $\begin{array}{l}\text { Poor } \\
\text { Responders } \\
(n=96)\end{array}$ & $\begin{array}{l}\text { Suboptimal responders } \\
(n=301)\end{array}$ & $\begin{array}{l}\text { Normal } \\
\text { Responders } \\
(n=386)\end{array}$ & $\begin{array}{l}\text { Oocyte } \\
\text { Donors } \\
(n=439)\end{array}$ \\
\hline Age (years): mean (SD) & $32.8(6.5)$ & $39.9(3.4)$ & $38.4(2.9)$ & $34.4(3.3)$ & $26(4.6)$ \\
\hline Weight (Kg) mean (SD) & $62.3(9.9)$ & $64.1(9.8)$ & $63.8(9.7)$ & $63.2(9.7)$ & $60.2(9.6)$ \\
\hline \multicolumn{6}{|l|}{$\begin{array}{l}\text { Cause of infertility } \\
\text { (\% vs total patients) }\end{array}$} \\
\hline Ovulatory & & $14.0 \%$ & $9.7 \%$ & $11.3 \%$ & \\
\hline Tubal & & $9.7 \%$ & $9.0 \%$ & $11.6 \%$ & \\
\hline Male & & $10.8 \%$ & $19.7 \%$ & $37.3 \%$ & \\
\hline Idiopathic & & $3.2 \%$ & $14.0 \%$ & $19.8 \%$ & \\
\hline Mixed / Other & & $62.3 \%$ & $47.6 \%$ & $20.0 \%$ & \\
\hline Baseline FSH IU/L (SD) & $7.4(2.9)$ & $8.9(4.2)$ & $8.0(3.7)$ & $6.9(2.0)$ & $5.4(2.8)$ \\
\hline $\mathrm{AMH}$ mean ng/ml (SD) & $2.8(2.6)$ & $0.9(0.7)$ & $1.9(1.8)$ & $3.4(2.8)$ & $4.6(2.5)$ \\
\hline
\end{tabular}

Note: Means \& percentages are based on the number of patients with non-missing data 
Table 3 Results of ovarian stimulation for patients reaching oocyte retrieval

\begin{tabular}{|c|c|c|c|c|c|}
\hline & $\begin{array}{l}\text { All women } \\
(n=1169)\end{array}$ & $\begin{array}{l}\text { Poor } \\
\text { Responders } \\
(n=88)\end{array}$ & $\begin{array}{l}\text { Suboptimal responders } \\
(n=274)\end{array}$ & $\begin{array}{l}\text { Normal } \\
\text { Responders } \\
(n=378)\end{array}$ & $\begin{array}{l}\text { Oocyte } \\
\text { Donors } \\
(n=429)\end{array}$ \\
\hline $\begin{array}{l}\text { Ovarian stimulation duration days } \\
\text { mean }( \pm S D)\end{array}$ & $\begin{array}{l}9.4 \\
(2.2)\end{array}$ & $\begin{array}{l}10.1 \\
(2.6)\end{array}$ & $\begin{array}{l}9.6 \\
(2.4)\end{array}$ & $\begin{array}{l}9.4 \\
(2.2)\end{array}$ & $\begin{array}{l}9.3 \\
(1.9)\end{array}$ \\
\hline $\begin{array}{l}\text { Total dose of r-FSH administered IU } \\
\text { mean }( \pm \text { SD) }\end{array}$ & $\begin{array}{l}2093.4 \\
(698.3)\end{array}$ & $\begin{array}{l}2423.2 \\
(937.1)\end{array}$ & $\begin{array}{l}2083.4 \\
(749.6)\end{array}$ & $\begin{array}{l}2040.3 \\
(752.9)\end{array}$ & $\begin{array}{l}2075.7 \\
(509.4)\end{array}$ \\
\hline $\begin{array}{l}\text { No. of retrieved oocytes } \\
\text { mean }( \pm \text { SD) }\end{array}$ & $\begin{array}{l}13.4 \\
(9.4)\end{array}$ & $\begin{array}{l}4.1 \\
(2.7)\end{array}$ & $\begin{array}{l}8.6 \\
(6.0)\end{array}$ & $\begin{array}{l}12.2 \\
(7.2)\end{array}$ & $\begin{array}{l}19.5 \\
(9.5)\end{array}$ \\
\hline $\begin{array}{l}\text { No. of MII oocytes } \\
\text { mean }( \pm S D)\end{array}$ & $\begin{array}{l}10.7 \\
(7.5)\end{array}$ & $\begin{array}{l}3.5 \\
(2.3)\end{array}$ & $\begin{array}{l}6.5 \\
(4.7)\end{array}$ & $\begin{array}{l}9.8 \\
(6.2)\end{array}$ & $\begin{array}{l}15.4 \\
(7.9)\end{array}$ \\
\hline
\end{tabular}

Note: Means \& percentages are based on the number of patients with non-missing data

diagnostic terminology [13]. Nevertheless, there were obvious differences seen between the populations of women in this study. The populations showed both quantitative and qualitative differences in terms of oocyte number achieved and embryo quality, respectively, associated with striking differences in implantation rates and pregnancy rates. This illustrates the value of assessing a new drug across a wide range of patients treated in diverse ways in real-world situations, as randomised control trials will include patients of often very limited prognoses, which may not be adequately balanced between study groups following randomisation, particularly if the sample size is relatively low, and which may not reflect the potential populations in real clinical practice. Furthermore, the study confirmed that Bemfola ${ }^{\circ}$ was able to meet the treatment requirements for all patient types whether using monotherapy or combination protocols.

Although this study adopted the Bologna criteria [10] to define the poor responder population, the limitations of this definition are acknowledged, which is why a further population of suboptimal responders was included in this study. Although the concept of poor ovarian response has been recognised for a very long time, in 2011 an enormous variability of the definitions of poor ovarian response in the literature was reported [14]. Thus in 2011 the European Society of Human Reproduction and Embryology (ESHRE) established strict criteria (Bologna consensus) to define poor ovarian response thereby establishing a more homogenous population to support research [10]. Although the Bologna criteria was a crucial step towards defining poor ovarian response, it became clear that even when using the Bologna criteria, the poor ovarian response population remained heterogeneous primarily because the criteria did not adequately take the age-related impact on oocyte quality into consideration, which significantly impacts success rates [15]. In 2016 a group of reproductive endocrinologists and scientists gathered to further refine the definition of poor ovarian response [16]. As a result, the new POSEIDON (Patient-Oriented Strategies Encompassing Individualized Oocyte Number) classification was developed, providing a more detailed classification to reduce the heterogeneity of the Bologna criteria [17]. When considering the definition of "poor ovarian response", the introduction of the follicular output rate

Table 4 Results of Insemination

\begin{tabular}{lllll}
\hline & $\begin{array}{l}\text { All women } \\
(n=642)\end{array}$ & $\begin{array}{l}\text { Poor } \\
\text { Responders } \\
(n=58)\end{array}$ & $\begin{array}{l}\text { Suboptimal responders } \\
(n=240)\end{array}$ & $\begin{array}{l}\text { Normal } \\
\text { Responders } \\
(n=344)\end{array}$ \\
\hline Number of fertilized oocytes mean $( \pm$ SD) & & 2.3 & 4.5 & 6.8 \\
$(4.8)$ & $(3.6)$ & $72.4 \%$ \\
$\begin{array}{l}\text { Fertilization rate (\%) } \\
\text { (number of fertilized oocytes / number of } \\
\text { inseminated or microinjected MIl oocytes) }\end{array}$ & & $71.7 \%$ & $68.4 \%$ & \\
$\begin{array}{l}\text { Number of embryos transferred } \\
1 \mathrm{n}(\%)\end{array}$ & $120(33.1 \%)$ & $12(36.4 \%)$ & $49(36.3 \%)$ & $59(30.3 \%)$ \\
$2 \mathrm{n}(\%)$ & $239(65.8 \%)$ & $21(63.6 \%)$ & $83(61.5 \%)$ & $135(69.2 \%)$ \\
$3 \mathrm{n}(\%)$ & $3(0.85)$ & $0(0 \%)$ & $3(2.2 \%)$ & $0(0 \%)$ \\
\hline
\end{tabular}

Note: Means \& percentages are based on the number of patients with non-missing data 


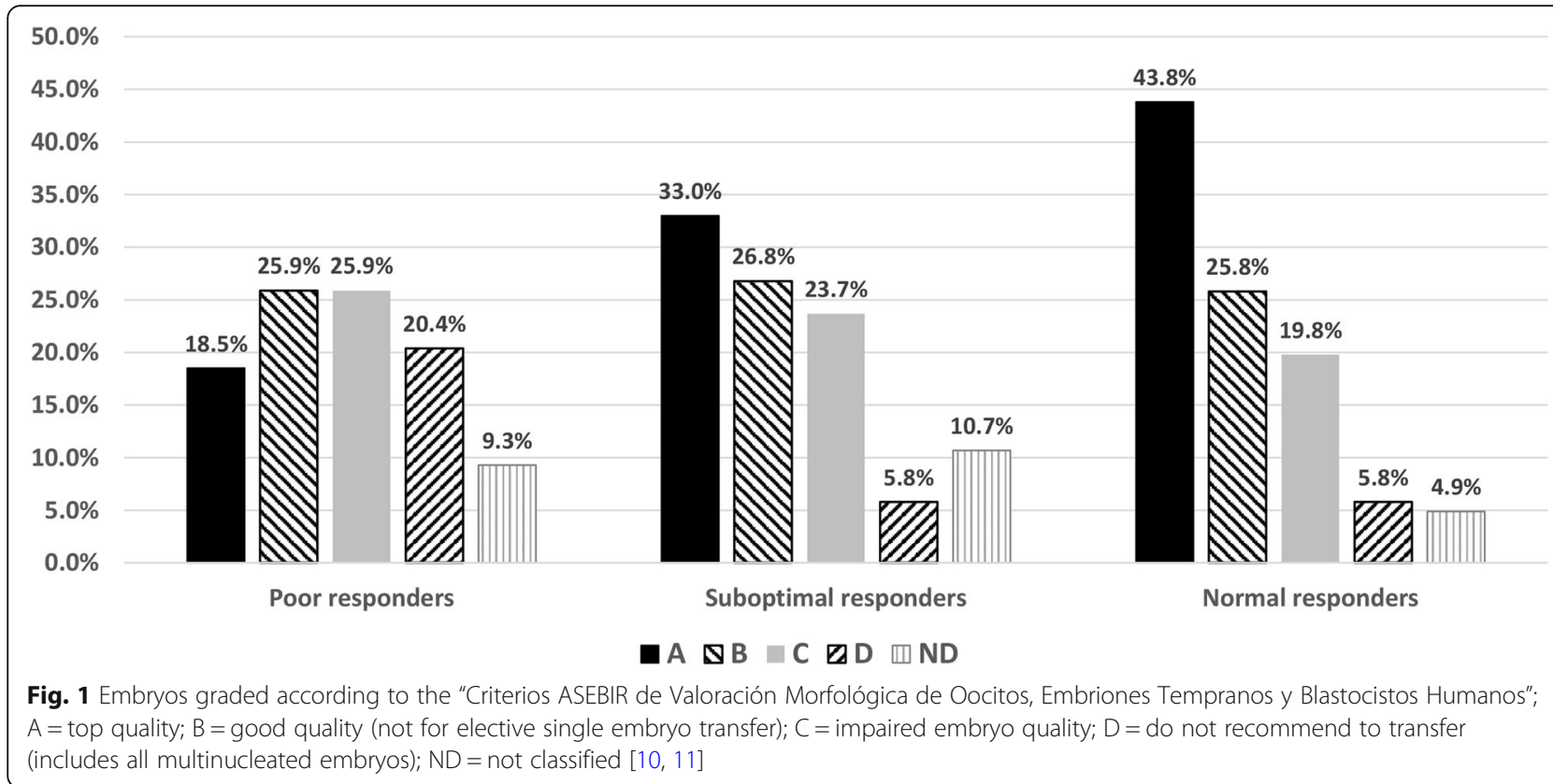

(FORT) [18] provides an alternative measure of ovarian response to exogenous stimulation by assessing the ratio between the number of pre-ovulatory follicles obtained in response to gonadotropin administration and the preexisting pool of small antral follicles. The FORT concept might even be taken a step further, including also the ratio between the final number of oocytes retrieved correlated to the antral follicle count (AFC) to measure successful ovarian response. As an example, a patient with a poor ovarian reserve who finally ends up with $70 \%$ of the antral follicles, resulting in retrieved oocytes has a high FORT, and in reality, a good ovarian response to stimulation regardless of the total number of oocytes retrieved. Evidentially, although the concept is clear, the precise definition of poor ovarian response remains a challenge. This paper presents two populations of relatively less than normal ovarian response demonstrating relatively poorer outcomes supportive of a heterogenous, continuum of ovarian responsiveness with associated differing prognoses rather than a discrete group of poor ovarian response patients.

No lack of efficacy nor pharmacovigilance signals were revealed in this real-world study of the use of this new product and in fact the differences between patient groups was far more relevant to whether a patient was successful with ART or suffered an adverse event than the choice of gonadotrophin. Furthermore, the pregnancy rates in the BIRTH study were consistent to the overall pregnancy rates per embryo transfer reported in 2017 to the national Spanish ART registry of $42 \%$, 36.5\% and $25.6 \%$ for IVF $(n=6473)$ and $44.5 \%, 36.3 \%$ and $21.2 \%$ for ICSI $(n=43,790)$ according to ages $<35$ years, $35-39$ years and $\geq 40$ years respectively [19]. The national overall multiple embryo transfer rates for Spain were $49 \%$ in 2016 and $44 \%$ in 2017 [19].

One area of particular interest explored in this study was the use of FSH with a product providing LH activity in what is referred to as combination, combo or mixed

Table 5 Pregnancy outcome

\begin{tabular}{|c|c|c|c|c|}
\hline & All women & $\begin{array}{l}\text { Poor } \\
\text { Responders }\end{array}$ & $\begin{array}{l}\text { Suboptimal } \\
\text { responders }\end{array}$ & $\begin{array}{l}\text { Normal } \\
\text { Responders }\end{array}$ \\
\hline $\begin{array}{l}\text { Implantation rates } \\
\text { (Total number of sacs / Total number of embryos transferred) }\end{array}$ & $\begin{array}{l}26.3 \% \\
(154 / 586)\end{array}$ & $\begin{array}{l}16.0 \% \\
(8 / 50)\end{array}$ & $\begin{array}{l}22.4 \% \\
(49 / 219)\end{array}$ & $\begin{array}{l}30.6 \% \\
(97 / 317)\end{array}$ \\
\hline $\begin{array}{l}\text { Clinical pregnancy (Total clinical pregnancies / Total number } \\
\text { of women with embryos transferred) }\end{array}$ & $\begin{array}{l}33.6 \% \\
(183 / 545)\end{array}$ & $\begin{array}{l}23.2 \% \\
(10 / 43)\end{array}$ & $\begin{array}{l}30.4 \% \\
(59 / 194)\end{array}$ & $\begin{array}{l}37.0 \% \\
(114 / 308)\end{array}$ \\
\hline \multicolumn{5}{|l|}{ Number of gestation sacs (\% vs total sacs) } \\
\hline 1 & $156(85.7 \%)$ & $10(100 \%)$ & $5389.8 \%)$ & $93(82.3 \%)$ \\
\hline 2 & $26(14.3 \%)$ & $0(0 \%)$ & $6(10.2 \%)$ & $20(17.7 \%)$ \\
\hline
\end{tabular}

Note: Means \& percentages are based on the number of patients with non-missing data 
Table 6 Age groups Monotherapy vs Combination Protocol

\begin{tabular}{lllll}
\hline Age & & $\begin{array}{l}\text { Monotherapy } \\
n=702(57.4 \%)\end{array}$ & $\begin{array}{l}\text { Combination }^{\text {a }} \\
n=520(42.6 \%)\end{array}$ & Total \\
\hline$<35$ years & $\mathrm{n}(\%)$ & $481(71.3 \%)$ & $194(28.7 \%)$ & 675 \\
35-<38 years & $\mathrm{n}(\%)$ & $114(47.5 \%)$ & $126(52.5 \%)$ & 240 \\
38- < 40 years & $\mathrm{n}(\%)$ & $49(30.4 \%)$ & $112(69.6 \%)$ & 161 \\
$>=40$ years & $\mathrm{n}(\%)$ & $58(39.7 \%)$ & $88(60.3 \%)$ & 146 \\
\hline
\end{tabular}

a addition of recombinant $\mathrm{LH}$ or HMG to $\mathrm{rFSH}$

protocols. The study showed combination protocols are commonly used in Spain, particularly in patients over 35 years of age or among patients anticipated to have a reduced response to ovarian stimulation. Although this study is not a randomised control study and there is considerable heterogeneity in terms of the details of the combination protocols used at different centres, the results are interesting to consider in the context of the literature and recent guidance on ovarian stimulation for IVF/ICSI from the European Society of Human Reproduction and Embryology [20].

In each BIRTH study population the implantation and pregnancy rates were numerically lower with combination protocols than with mono therapy. Although statistical comparisons of these results would be inappropriate as patients allocated to combination protocols might be of a poorer prognosis even within patient populations, at the very least the results do not suggest any benefit for combination protocols in any of the patient populations studied. The ESHRE ovarian stimulation for IVF/ICSI guidelines similarly could not identify any groups that would benefit from the addition of LH activity to FSH stimulation, other than the rare cases of WHO-I anovulatory patients. The ESHRE ovarian stimulation for IVF/ICSI guidelines specifically commented there was no evidence of a beneficial effect on live birth rates for the $\mathrm{LH}$ supplementation of $\mathrm{rFSH}$ in poor responders or women of advanced age. In addition and of note, the ESPART Study in "poor responders" suggested fewer oocytes with LH and no benefit in pregnancy rates [21] and a meta-analysis of 5840 patients in twenty-nine studies confirmed LH reduced number of oocytes when added to FSH [22]. A further large randomised trial, MEGASET, showed that not only was the addition of LH activity associated with fewer oocytes, but there was no benefit in the quality of oocytes, embryos and blastocysts [23].

This evidence of clinical effectiveness from this study is particularly important as further to Bemfola ${ }^{\circ}$ being approved by the European Medicines Agency in 2014 as a biosimilar of follitropin alpha, in 2017 the Bemfola ${ }^{\circ}$ drug substance batch number T128/FSH/B1 was adopted as the European Follitropin Chemical Reference Substance (CRS) $[24,25]$. The drug substance is essentially the active pharmaceutical ingredient (API) or the 'naked' drug without excipients. The API is what will have a therapeutic effect inside the body as opposed to the excipients that serve to package and deliver the API. The drug product is the formulated mixture of the drug substance and excipients which results in the final marketed product. The quality and consistency of any rFSH drug substance prior to release of the final $\mathrm{rFSH}$ drug product may be assessed against the Follitropin CRS according to the European Pharmacopoeia (Ph.Eur) of the European Directorate for the Quality of Medicines and Healthcare (EDQM).

Although a real world study has the advantage of reporting on the whole highly heterogeneous population receiving a very diverse range of clinical ART practices, inevitably this leads to study limitations of low internal validity, lack of quality control and susceptibility to multiple sources of bias. Further the BIRTH study did not present spontaneous abortion rates, live birth rates and rates of congenital anomalies. Hence, real world studies such as the BIRTH study should be viewed as part of a wider body of evidence to guide clinical practice.

\section{Conclusions}

Fertility is a continuum from poor responders, suboptimal responders, normal responders through to fertile oocyte donors. Bemfola produced the anticipated number of oocytes according to patients' populations with adequate embryo quality and pregnancy rates in a real

Table 7 Results of ovarian stimulation - Monotherapy vs Combination Protocol

\begin{tabular}{llllll}
\hline & All women & $\begin{array}{l}\text { Poor } \\
\text { Responders }\end{array}$ & Suboptimal responders & $\begin{array}{l}\text { Normal } \\
\text { Responders }\end{array}$ & $\begin{array}{l}\text { Oocyte } \\
\text { Donors }\end{array}$ \\
\hline Monotherapy & $(n=681)$ & $(n=40)$ & $(n=89)$ & $(n=234)$ & $(n=318)$ \\
No. of retrieved oocytes mean & 15.1 & 3.7 & 9.9 & 13.6 & $(7.6)$ \\
$( \pm$ SD) & $(9.4)$ & $(2.6)$ & $(7.2)$ & $(n=14)$ & $(9.5)$ \\
Combination & $(n=488)$ & $(n=48)$ & 7.9 & 10.1 & $(n=111)$ \\
$\begin{array}{l}\text { No. of retrieved oocytes mean } \\
( \pm \text { SD) }\end{array}$ & 11.2 & 4.6 & $(5.2)$ & $(6.1)$ & 20.8 \\
\hline
\end{tabular}

Note: Means \& percentages are based on the number of patients with non-missing data 
Table 8 Pregnancy outcome - Monotherapy vs Combination Protocol

\begin{tabular}{|c|c|c|c|c|}
\hline & All women & $\begin{array}{l}\text { Poor } \\
\text { Responders }\end{array}$ & Suboptimal responders & $\begin{array}{l}\text { Normal } \\
\text { Responders } \\
\end{array}$ \\
\hline \multicolumn{5}{|l|}{ Monotherapy } \\
\hline Implantation rates & $32.8 \%$ & $25.0 \%$ & $22.9 \%$ & $35.7 \%$ \\
\hline (Total number of sacs / Total number of embryos transferred) & $(79 / 241)$ & $(2 / 8)$ & $(11 / 48)$ & $(66 / 185)$ \\
\hline Clinical pregnancy rate & $38.8 \%$ & $27.3 \%$ & $35.6 \%$ & $40.4 \%$ \\
\hline $\begin{array}{l}\text { (Total clinical pregnancies / Total number of women with } \\
\text { embryos transferred d) }\end{array}$ & $(100 / 258)$ & $(3 / 11)$ & $(21 / 59)$ & $(76 / 188)$ \\
\hline \multicolumn{5}{|l|}{ Combination } \\
\hline Implantation rates & $21.7 \%$ & $14.3 \%$ & $22.2 \%$ & $23.5 \%$ \\
\hline (Total number of sacs / Total number of embryos transferred) & $(75 / 345)$ & $(6 / 42)$ & $(38 / 171)$ & $(31 / 132)$ \\
\hline Clinical pregnancy rate & $28.9 \%$ & $21.9 \%$ & $28.1 \%$ & $31.7 \%$ \\
\hline $\begin{array}{l}\text { (Total clinical pregnancies / Total number of women with } \\
\text { embryos transferred) }\end{array}$ & $(83 / 287))$ & $(7 / 32)$ & (38/135) & $(38 / 120)$ \\
\hline
\end{tabular}

Note: Means \& percentages are based on the number of patients with non-missing data

world setting which were consistent with Spanish national ART reports. In addition a low rate of adverse reactions were reported. The results seen regarding the use of combination protocols reflect the medical literature and recent guidance from ESHRE questioning the value of adding LH activity to gonadotrophin stimulation protocols [20].

\section{Abbreviations}

AFC: Antral follicle count; AMH: Anti-Müllerian hormone; ART: Assisted Reproductive Technology; ASEBIR: Asociación para el Estudio de la Biología de la Reproducción; CRS: Chemical Reference Substance; EDQM: European Directorate for the Quality of Medicines and Healthcare; EMA: European Medicines Agency; ESHRE: European Society for Human Reproduction and Embryology; FSH: Follicle stimulating hormone; ICSI: Intracytoplasmic sperm injection; IVF: In vitro fertilization; LH: Luteinizing hormone; OHSS: ovarian hyperstimulation syndrome; Ph.Eur: European Pharmacopoeia; SD: Standard deviation; SEF: Sociedad Española de Fertilidad

\section{Acknowledgements}

The study data was collected and analysed by Dynamic, Azcona, 31, 28028 Madrid, Spain.

\section{Authors' contributions}

All authors contributed to the design of the study, execution of the study and/or drafting of the publication and all authors confirm the validity of the results. The author(s) read and approved the final manuscript.

\section{Funding}

The BIRTH study was funded by Gedeon Richter Ibérica S.A., Pedro i Pons 911, 7a planta, 08034 Barcelona, Spain.

\section{Availability of data and materials}

The datasets used in the current study are available from the corresponding author on reasonable request.

\section{Ethics approval and consent to participate}

The study was approved by the Ethics Committee of Clinical Research of Euskadi and written informed consent was obtained from all participants.

\section{Consent for publication}

Not applicable.

\section{Competing interests}

$J J$ is a medical advisor to Preglem SA / Gedeon Richter. The remaining authors declare that they have no competing interests.

The data analysis was performed by the Contract Research Organisation, Dynamic, under the direction of the Medical Affairs department of Preglem SA / Gedeon Richter and the final manuscript was drafted by the Medical Affairs department in collaboration with the authors; in both cases there was no involvement of Preglem SA / Gedeon Richter marketing or commercial teams.

\section{Author details}

${ }^{1}$ IVI-RMA, Bilbao, Spain. ${ }^{2}$ Servicio de Medicina de la Reproducción of Hospital Universitari Quirón Dexeus, Barcelona, Spain. ${ }^{3}$ Unidad de Reproducción of Hospital Clínico Universitario de Valladolid, Valladolid, Spain. ${ }^{4}$ Reproducción Bilbao, Universidad del País Vasco/Euskal Herriko Unibertsitatea, Bilbao, Spain. ${ }^{5}$ Barcelona IVF, Barcelona, Spain. ${ }^{6}$ Ginemed, Sevilla, Spain. ${ }^{7}$ Gedeon Richter/ Preglem S.A., Gedeon Richter/ Preglem SA, Route de Frontenex 41A, 1207 Geneva, Switzerland.

Received: 24 April 2020 Accepted: 10 July 2020

Published online: 29 July 2020

\section{References}

1. De Geyter C, Calhaz-Jorge C, Kupka MS, Wyns C, Mocanu E, Motrenko T, Scaravelli G, Smeenk J, Vidakovic S, Goossens V. ART in Europe, 2014: results generated from European registries by ESHRE. Hum Reprod. 2018;33:1586-601.

2. Foxon G, Mitchell P, Turner N, McConnell A, Kendrew H, Jenkins J. Bemfola ${ }^{\circledR}$ fixed dose pens potentially reduce drug wastage and associated costs of infertility treatment. Hum Fertil (Camb). 2018;21:275-80.

3. de Mora F, Fauser BCJM. Biosimilars to recombinant human FSH medicines: comparable efficacy and safety to the original biologic. Reprod Biomed Online. 2017;35:81-6.

4. Quintero LA, Merino W, de la Fuente Bitaine L, Olivares Vela RO, Rayward J, Torres Afonso AT, Báez Quintana DB, Pinochet CA, Giménez MAG, Trías AG, Jenkins J. An evaluation by potential IVF/Donor Oocyte patients of the Use and Handling of the Bemfola ${ }^{\circledast}$ Pen compared with the Gonal-f® Pen and Puregon Pen ${ }^{\oplus}$ Revista Iberoamericana de Fertilidad y Reproducción Humana / Vol. 33 n 3 Julio-Agosto-Septiembre 2016.

5. European Medicines Agencies (EMA) Guideline on non-clinical and clinical development of similar biological medicinal products containing recombinant human follicle stimulating hormone (r-hFSH) 21 February 2013 EMA/CHMP/BMWP/671292/2010 https://www.ema.europa.eu/en/ similar-biological-medicinal-products-containing-recombinant-folliclestimulating-hormone. Accessed 13 July 2020.

6. Wolzt M, Gouya G, Sator M, Hemetsberger T, Irps C, Rettenbacher M, et al, Comparison of pharmacokinetic and safety profiles between Bemfola ${ }^{\oplus}$ and 
Gonal-fø after subcutaneous application. Eur J Drug Metab Pharmacokinet. 2016;41:259-65.

7. Rettenbacher M, Andersen AN, Garcia-Velasco JA, Sator M, Barri P, Lindenberg S, van der Ven K, Khalaf Y, Bentin-Ley U, Obruca A, Tews G, Schenk M, Strowitzki T, Narvekar N, Sator K, Imthurn B. A multi-Centre phase 3 study comparing efficacy and safety of Bemfola ${ }^{\otimes}$ versus Gonal-f® in women undergoing ovarian stimulation for IVF. Reprod BioMed Online. 2015:30:504-13.

8. Haynes B. Can it work? Does it work? Is it worth it? The testing of healthcare interventions is evolving. BMJ. 1999:319:652-3.

9. European Medicines Agencies (EMA) Network Strategy to 2020 Working together to improve health EMA/MB/151414/2015. https://www.ema. europa.eu/en/documents/other/eu-medicines-agencies-network-strategy-2 020-working-together-improve-health_en.pdf. Accessed 13 July 2020.

10. Ferraretti AP, La MA, Fauser BC, Tarlatzis B, Nargund G, Gianaroli L. ESHRE consensus on the definition of 'poor response' to ovarian stimulation for in vitro fertilization: the Bologna criteria. Hum Reprod. 2011;26:1616-24.

11. ASEBIR: Asociación para el Estudio de la Biología de la Reproducción. CUADERNOS DE EMBRIOLOGIA CLINIICA. Criterios ASEBIR de Valoración Morfológica de Ovocitos, Embriones Tempranos y Blastocitos Humanos. [3a]. 2015. https:/asebir.com/cuadernos-asebir/criterios-asebir-de-valoracionmorfologica-de-oocitos-embriones-tempranos-y-blastocistos-humanos.

12. Alpha Scientists in Reproductive Medicine and ESHRE Special Interest Group of Embryology. The Istanbul Consensus Workshop on Embryo Assessment: Proceedings of an Expert Meeting. Hum Reprod. 2011;26:1270-83.

13. Jenkins J, Daya S, Kremer J, Balasch J, Barratt C, Cooke I, Lawford-Davies J, De Sutter P, Suikari AM, Neulen J, Nygren K. European classification of infertility taskforce (ECIT) response to Habbema et al., 'Towards less confusing terminology in reproductive medicine: a proposal'. Hum Reprod. 2004;19:2687-8.

14. Polyzos NP, Devroey P. A systematic review of randomized trials for the treatment of poor ovarian responders: is there any light at the end of the tunnel? Fertil Steril. 2011;96:1058-1061.e7.

15. Bozdag G, Polat I, Yarali I, Yarali H. Live birth rates in various subgroups of poor ovarian responders fulfilling the Bologna criteria. Reprod BioMed Online. 2017;34:639-44.

16. Alviggi C, Andersen CY, Buehler K, Conforti A, De Placido G, Esteves SC, Fischer R, Galliano D, Polyzos NP, Sunkara SK, Ubaldi FM, Humaidan P. Poseidon group (patient-oriented strategies encompassing individualized oocyte number) a new more detailed stratification of low responders to ovarian stimulation: from a poor ovarian response to a low prognosis concept. Fertil Steril. 2016;105:1452-3.

17. Haahr T, Esteves SC, Humaidan P. Poor definition of poor-ovarian response results in misleading clinical recommendations. Hum Reprod. 2018;33:979-80

18. Gallot V, Berwanger da Silva AL, Genro V, Grynberg M, Frydman N, Fanchin R. Antral follicle responsiveness to follicle-stimulating hormone administration assessed by the follicular output RaTe (FORT) may predict in vitro fertilization-embryo transfer outcome. Hum Reprod. 2012;27:1066-72.

19. Sociedad Española de Fertilidad (SEF). Informe estadístico de Técnicas de Reproducción Asistida 2017. https://cnrha.sanidad.gob.es/registros/pdf/ Informe_estadisticoSEF_2017.pdf. Accessed 13 July 2020.

20. ESHRE Guideline on ovarian stimulation for IVF/ICSI October 2019. https:/ www.eshre.eu/Guidelines-and-Legal/Guidelines/Ovarian-Stimulation-in-IVF-ICSI. Accessed 13 July 2020.

21. Humaidan P, Chin W, Rogoff D, D'Hooghe T, Longobardi S, Hubbard J, Schertz J. Efficacy and safety of follitropin alfa/lutropin alfa in ART: a randomized controlled trial in poor ovarian responders. Hum Reprod. 2017; 32:544-55.

22. Santi $D$, Casarini L, Alviggi C, Simoni M. Efficacy of follicle-stimulating hormone (FSH) alone, FSH + luteinizing hormone, human menopausal gonadotropin or FSH + human chorionic gonadotropin on assisted reproductive technology outcomes in the "personalized" medicine era: a meta-analysis. Front Endocrinol. 2017;8:114. https://doi.org/10.3389/fendo. 2017.00114.

23. Devroey P, Pellicer A, Nyboe Andersen A, Arce JC. Menopur in GnRH antagonist cycles with single embryo transfer trial group. A randomized assessor-blind trial comparing highly purified hMG and recombinant FSH in a GnRH antagonist cycle with compulsory single-blastocyst transfer. Fertil Steril. 2012;97:561-71.
24. European Directorate for the Quality of Medicines \& HealthCare (EDQM). Information Leaflet Ph. Eur. Reference Standard Follitropin Chemical Reference Substance batch 2. Strasbourg; 2017. https://crs.edqm.eu/db/4 DCGI/Niew=Y0001629. Accessed 13 July 2020.

25. European Directorate for the Quality of Medicines \& HealthCare (EDQM). Laboratory Report: Establishment of follitropin for peptide mapping and glycan analysis Follitropin Chemical Reference Substance 2. European Pharmacopoeia Commission. Strasbourg: EDQM report; 2018.

\section{Publisher's Note}

Springer Nature remains neutral with regard to jurisdictional claims in published maps and institutional affiliations.

\section{Ready to submit your research? Choose BMC and benefit from:}

- fast, convenient online submission

- thorough peer review by experienced researchers in your field

- rapid publication on acceptance

- support for research data, including large and complex data types

- gold Open Access which fosters wider collaboration and increased citations

- maximum visibility for your research: over $100 \mathrm{M}$ website views per year

At $\mathrm{BMC}$, research is always in progress.

Learn more biomedcentral.com/submissions 